\title{
Puccinia malvacearum and the Mycoplasm Theory.
}

\author{
BY \\ M. A. BAILEY, B.A., Cantab. \\ With two Figures in the Text. \\ INTRODUCTION.
}

THE sudden and widespread appearance, year after year, of certain 1 parasitic fungi is a phenomenon which has been recognized for many years and has given rise to the keenest controversy and speculation.

The mode of origin of these epidemics is very difficult to discover, and the question is rendered more complex owing to the fact that the fungi concerned are often extremely narrowly specialized and that their spores frequently show a very limited period of viability.

After a lengthy series of experiments on the Rusts of various species of Gramineae, Eriksson brought forward the Mycoplasm Hypothesis in explanation of the observed facts.

This hypothesis was first asserted by him in 1897 , but has been developed and enlarged upon subsequently to include other fungi in addition to the Cereal Rusts.

In I9I I Eriksson published a monograph on Puccinia malvacearum, in which he applied this theory to account for the yearly origin and dissemination of the Hollyhock Rust, and more recently a similar explanation has been put forward by him in the case of the Potato Disease Fungus, Phytophthora infestans. ${ }^{2}$ Briefly stated, his suggestion is that the fungus, in certain cases, is able to spend part of its vegetative life in the form of naked protoplasm in the interior of the cells of the host, existing there in a symbiotic state.

When in this condition the fungus is said to have assumed the mycoplasmic state, and this mycoplasm permeates the whole of the plant tissues, including the developing embryo.

1 Eriksson : Der Malvenrost; seine Verbreitung, Natur und Entwickelungsgeschichte. Kungl. Svenska Vetenskapsakademiens Handlingar, Band xlvii, No. 2.

${ }^{2}$ Eriksson: Développement primaire du mildiou (Phytophthora infestans) de la pomme de erre. Rev. Gén. de Botanique, tomes xxix and xxx.

[Annals of Botany, Vol. XXXIV. No. CXXXIV. April, 1920.] 
When the seed germinates in the following season, the fungus protoplasm divides with the cytoplasm of the host cells and is in this way distributed throughout the tissues of the seedling plant.

Later on, when the growing plant reaches a certain stage of maturity, the fungus reverts to the mycelial condition preparatory to the production of spores.

The theory is exceedingly attractive and is backed by a mass of data derived from experimental inoculation and histology. If proved correct, it would have most far-reaching effects in modifying the theory and practice of the control of plant disease.

Eriksson's hypothesis has, however, many opponents, and certain isolated experimental results, recorded by other investigators, suggest that the facts can be explained by other and simpler means.

It was with the idea of throwing further light on this subject that the experiments described in the present paper were started.

The experiments were interrupted by the war, and there seems, unfortunately, to be little chance of repeating them in the near future, but the evidence obtained is, in many cases, in such marked opposition to the observations and deductions made by Eriksson as to seem to warrant publication in some detail.

The work was carried out at the John Innes Horticultural Institution, where I was given every facility through the kindness of Mr. Bateson.

I should like to take this opportunity of thanking Mrs. Scott Tucker and Miss D. M. Cayley for great assistance rendered in the recording of results during the later stages of the experiments.

An extensive bibliography is considered to be unnecessary in this paper, as a list of the more important literature will be found at the end of Eriksson's paper on 'Der Malvenrost', already referred to.

\section{Discussion OF ERIKSSON'S WORK ON THE HOLlyHOCK RUST.}

In his paper on the Hollyhock Rust, Eriksson emphasizes a number of points which he considers as affording strong evidence of the existence of a mycoplasmic stage in the life-history of the fungus. These points are enumerated below, where they are considered in the light of further evidence.

I. Sudden appearance of the disease in epidemic form. This has long been recognized by many observers. Eriksson states that the interval between the sowing of the seed and the appearance of the disease in quantity is extremely regular and varies only with the time of year. Seed sown in Sweden at the end of June produced plants on which the rust appeared regularly about three months later. On no occasion did the plants show rust earlier than three months after germination, except in those cases where they were grown close to other plants which were already suffering from the disease. 
Seed sown in September germinated the same year, and the young plants, if kept in boxes in a cold house during the winter, did not show any trace of disease till the following May.

2. Limitation of disease outbreak to leaves of a certain age. 'Primary' and 'secondary' development. Eriksson calls attention to the fact that the leaves of affected plants show little or no infection whilst young, but when they arrive at a stage approaching maturity they become densely covered with pustules of the rust. Leaves that escape infection at this time never seem to become heavily infected.

The conclusion that Eriksson draws from these observations is that the sudden appearance of great quantities of qustules on the middle-aged leaves represents the separation of the mycoplasm existing within the leaf tissues and its differentiation into vegetative and reproductive mycelium. The sporadically distributed pustules appearing on leaves of various ages he attributes to outside infection. These observations have been confirmed in part by the present writer, but the conclusion drawn is that the metabolism of the middle-aged leaf is such as to render it much more susceptible to attack than younger or older leaves. This conclusion is supported by observations made in the present season on the incidence of rust upon wild plants of Malva sylvestris.

About a dozen plants altogether were found and marked for future record. These will be referred to by letters as shown below :

'A.' Four plants growing within a radius of 8 feet of one another.

'B.' Two plants growing close together at a place half a mile distant from ' $A$ '.

' C.' Two plants close together about half-way between ' $A$ ' and ' $B$ '.

'D.' Five plants scattered at long intervals over an area situated almost a mile from any of the above.

When first observed, on the I 4 th of May, one of the 'A ' plants showed a few young pustules on four leaves (one of which was still quite young).

One leaf of one of the ' $C$ ' plants was similarly affected.

On May 20 all the middle-aged leaves of the plant of the 'A' group mentioned above were affected, carrying an average of 30 pustules apiece. Some of the younger leaves of the same plant also showed a few pustules. The plant nearest this one in the same group showed a few pustules sporadically distributed. The infected plant in the 'C' group showed a slight general increase of disease. None of the other plants showed disease.

On May 26 the first infected plant in 'A' group showed dense masses of pustules on all its middle-aged leaves and sporadic infection on most of the younger and some of the older leaves. The plant next to it was in practically the same condition, and both answered the description of 'primary infection' given in Eriksson's paper. Of the other two plants in 
group ' $\mathrm{A}$ ' one showed slight infection of the mature leaves and the other one showed a few pustules only. The plant in group ' $\mathrm{C}$ ' previously recorded as slightly infected now showed a degree of infection corresponding to rather heavy 'secondary infection' in Eriksson's description. One of the plants in group ' $B$ ' and one of the isolated plants referred to in the original description under the letter ' $\mathrm{D}$ ' now showed one or two pustules on middle-aged vigorous leaves. The above account summarizes the appearance of these plants on the dates given: seen from day to day the impression was even more forcibly conveyed that this was a case of disease spreading from one plant to another by means of a normal process of infection, either from the plants originally recorded as diseased, or from others in the vicinity, which had been overlooked.

The transition in the case of the two heavily infected plants in group 'A' from a state of moderate infection of 'secondary' type to that resembling very heavy 'primary infection' was rapid, but showed all intermediate stages. All these plants arose from perennial root stocks, and in the case of group 'A ' they grew in a yard which was known to have contained heavily diseased plants of Malva sylvestris for several years previously.

3. Sudden appearance of disease in bulk in places far removed from outside sources of infection. The facts given by Eriksson are remarkable, but the observations just recorded above show that in cases of 'normal' infection the infective material can be and often is carried long distances, and that the appearance of the first few isolated pustules is followed very rapidly by conditions of intense infection. Moreover, these records show the existence of a relatively large amount of infective material, in this country at least, at an early period in the season of growth.

4. Non-viability of teleutospores which have passed through the winter without germinating. It is an established fact that the vast majority of over-wintered spores of this fungus lose their power of germination. Eriksson quotes the work of previous investigators in support of this, and records a few cases in which he himself tried to germinate such spores, but without success. The experience of the present author points in the same direction. Eriksson, however, quotes Fischer as finding germinable teleutospores as far through the winter as January $3^{1}$, and Taubenhaus ${ }^{1}$ in America has shown that such spores can be germinated as late as April in the year following their formation. The last named points out that the older the spore is the longer it takes to germinate, and suggests that previous negative results might likely be explained on the assumption that the teleutospores had not been left long enough in the drops of water.

That this delayed germination takes place but sparingly in nature is to

1 Taubenhaus:- Puccinia malvacearum, Mont. Phytopathology, vol. i, No. z. 
be inferred from an experiment conducted by Dandeno, ${ }^{1}$ who scattered a large quantity of dead leaves and stems of mallows, which had been diseased the previous autumn, amongst patches of mallows which were just commencing to grow in the following spring. The infected litter produced no result.

5. Absence of mycelium in seeds and young plants. Eriksson made numerous sections of both seeds and young plants, and failed in every case to find any trace of mycelium.

Though it may be taken as an established fact that the fungus does not pass through the winter in a mycelial condition in the seed, there is evidence to suggest that in certain cases the mycelium persists in the stems and leaves of hollyhock or mallow plants growing in positions where they are sheltered by surrounding vegetation or litter. Taubenhaus ${ }^{2}$ records a case in which he found living mycelium and even immature teleuto-sori throughout the winter and early spring in hollyhock leaves which had been mulched with horse manure.

It may easily be imagined that the comparatively few spores which are needed to start the initial infection are derived chiefly from such persistent mycelium, though a certain proportion of spores doubtless survive the winter and germinate direct in the following spring.

6. Dimorphism in teleutospores. Eriksson found that teleutospores differed in the mode of their germination. Either a short thick septate promycelium is formed, which abstricts small pear-shaped sporidia from each of its segments, or a comparatively long thin promycelial tube may arise, which is marked by the fact that its base is frequently somewhat swollen and that it never produces sporidia.

In this latter case the distal end of the tube divides up into three or four oblong segments which ultimately fall apart in a way which strongly recalls the formation of oidia in the Erysiphaceae.

Taubenhaus also describes the formation of these 'oidia', and states that they subsequently germinate to form sporidia, which in turn germinate by the production of germ tubes.

The present writer has been unable to confirm this last observation of Taubenhaus, but has frequently seen 'oidia' germinating direct by means of germ tubes.

Eriksson lays very great stress on this dimorphism in promycelia, though he admits that the two forms of germination may sometimes be found in the same pustule. He states that spores taken in spring from pustules on plants which have been wintered over in greenhouses-and in which the fungus has consequently continued to live-germinate mostly

1 Dandeno: Life-history of Puccinia malvacearum. Ninth Annual Report Mich. Acad. Sci., 1907.

2 Loc. cit, 
with the production of promycelia and sporidia; sometimes 'oidial' germination may be found to occur in the same pustule, and occasionally all the germination in any one pustule will be of the oidial type. On the other hand, he says, spores taken from pustules which had broken out on plants which had passed the winter out of doors and had lost their leaves in the normal way, germinate almost always with 'oidia'.

These conclusions are supported by a long table containing the results of 34 experiments, but the evidence is not very convincing owing to the frequent occurrence of both sorts of germination from one pustule and to the fact that in certain cases one pustule has given entirely sporidial germination, whilst another from the same plant has given entirely oidial germination.

The present writer has conducted a fairly extensive series of germination experiments, the details of which will be found in the Appendix to this paper.

The deduction made from these experiments is that the 'oidial' type of germination is merely the result of abnormal conditions and can be produced at will by varying the environment.

If the teleutospores are completely submerged in water, germination will be almost exclusively of the 'oidial' type, whilst the same spores, exposed to moist air, will produce promycelia and sporidia in the normal way.

The experiments are divided into six series. In the first three series, spores, teased apart or united in pustules, were placed either on or under the surface of water in watch-glasses. It may be assumed in this case that all those spores which remained at the bottom of the water were thoroughly wetted, whilst those which floated on the surface were either partially or wholly wet or, less frequently, quite dry.

An examination of the results of these three series shows that spores which remained at the bottom of the water germinated exclusively in the 'oidial' manner, whilst those at the surface germinated in either one way or the other. In almost all cases the spores on the surface showed a mixed germination, and in a few cases the two cells of the one spore germinated differently. One such case is illustrated in Fig. I.

Eriksson, in his description of the oidial type of germination, calls attention to the swelling at the proximal end of the germ tube. In our own cultures this swelling has frequently been noticed, but is by no means an invariable feature of this type.

In Series IV and V complete leaves were detached from diseased plants and supported in such a way that one half of each leaf was submerged in water whilst the other half was exposed to the air.

The air around the leaves was kept thoroughly moist by covering the whole with a large bell-jar. Series VI was carried out similarly with 
detached leaves, but in this case one leaf was entirely submerged, whilst another similar leaf from the same plant was kept in moist air. The results of these three series were uniform in one respect: in every case the pustules which were exposed to the air germinated to form promycelia and sporidia in the normal manner. The behaviour of the submerged leaves or portions of leaves was not so regular; sometimes oidia only were produced, some-
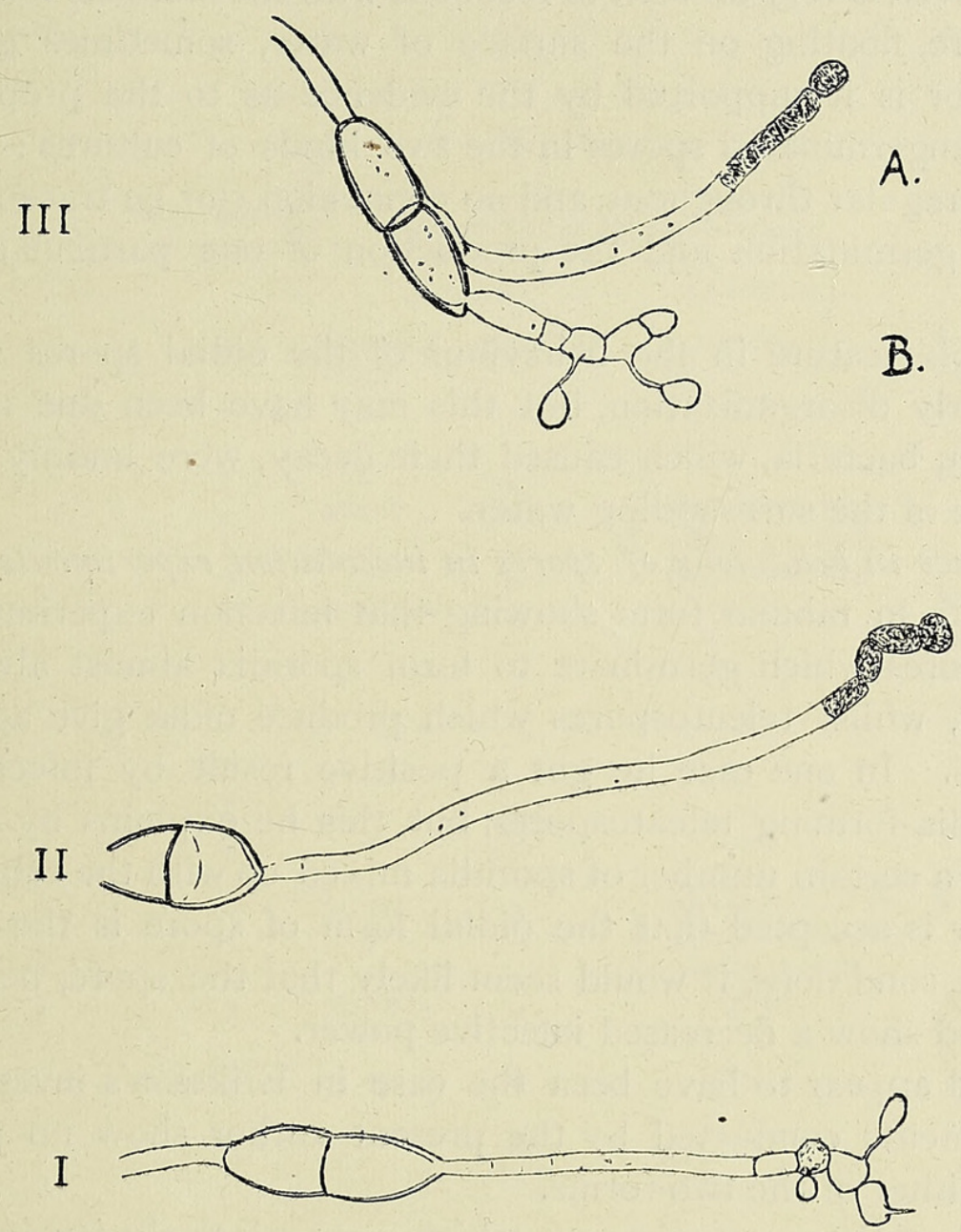

FIG. I. Teleutospores of Puccinia malvacearum germinated in sterile tap-water in a watch-glass,

I. Shows typical sporidial germination of a spore lying on surface of water.

II. 'Oidial 'germination of a spore at bottom of watch-glass.

III. Shows 'oidial' germination (A) from the proximal cell (whole of germ tube under surface of water) and sporidial germination (B) from distal cell (the three last segments of the germ tube are above the surface of the water).

$$
\text { (Magnification, } 380 \text { diameters.) }
$$

times a mixture of oidia and abortive germ tubes, more or less intermediate between the two types, and sometimes, but much more rarely, a normal crop of sporidia was formed.

These apparent irregularities are without doubt due to one of two causes : either the whole surface of the leaf was not in every case thoroughly wetted, or the pustules had already started to germinate before they were submerged. That this is the correct interpretation cannot be doubted when 
the absolute regularity of behaviour of the submerged spores in Series I to III ( 7 cases) and of the exposed spores in the remaining series (93 pustules) is taken into account.

- An alternative explanation is that the pustules contain spores which can only germinate in one way or the other, and that sporidial germination is inhibited by very wet conditions and vice versa.

This, however, is very difficult to reconcile with the fact that the two cells of a single spore, floating on the surface of water, sometimes germinate differently. Nor is it supported by the evidence as to the proportion of germinated to ungerminated spores in the two kinds of cultures : germination was very irregular throughout, and no connexion can be traced between full and scanty germination and the production of one particular kind of spore

A noticeable feature in the behaviour of the oidial spores was their tendency to early disorganization, but this may have been due merely to the fact that the bacteria, which caused their decay, were unduly favoured by the presence of the surrounding water.

7. Difference in behaviour of spores in inoculation experiments. Eriksson gives results in tabular form showing that infection experiments with those teleutospores which germinate to form sporidia almost always give positive results, whilst teleutospores which produce oidia give apparently negative results. In one case he got a positive result by infecting with a pustule of oidia-forming teleutospores, but this he explains by assuming that there were a certain number of sporidia mixed up with the other spores.

If the view is accepted that the oidial form of spore is the result of abnormally wet conditions, it would seem likely that the spore, being itself abnormal, would show a decreased infective power.

This would appear to have been the case in Eriksson's investigations, but the experiments conducted by the present author show no particular prepotence of either of the two forms.

The results of these experiments, which were relatively few in number, are given in tabular form below. They were carried out during a spell of very hot weather under conditions which were not very favourable to the fungus.

The method used was that described by Eriksson in his paper. Each leaf was inoculated in six places-three on either side of the midrib. The inoculations on the right side of the midrib were carried out with pustules which had germinated to form sporidia only, whilst those on the left side were carried out with pustules which had produced oidia only.

The plants used were hollyhocks, bearing about twelve leaves apiece and just beginning to send up flowering spikes. Inoculations were made on the upper surface of the leaves.

One leaf only of each plant was inoculated in the manner described, 


\section{Bailey.-Puccinia malvacearum and the Mycoplasm Theory. I $8 \mathrm{I}$}

the rest being kept as controls. No rust appeared on any of the uninoculated leaves during the experiment.

One pustule was used for each inoculation, and these were taken from leaves which had been kept for some time previously either submerged in water or exposed to a damp atmosphere.

The mode of germination of the teleutospores was ascertained by microscopical examination before the pustules were employed for purposes of inoculation.

TABLE I. Date. Plant No. Inoculation

3.6.19.

I

sporidial germination

Material used for inoculation.

Resulls.

Nature.

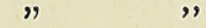

oidial

,"

,

2

4.6. 19.

8

$$
\text { , }
$$

oidial

,"

sporidial

"
",
"
"

$\left\{\begin{array}{l}\text { oidia showed ten- } \\ \text { dency to disor- } \\ \text { ganize rapidly }\end{array}\right.$ good

good

,

oidia showed ten-
dency to disor-
ganize rapidly
guod

dency to disorganize rapidly good

\section{Condition.}

"

$"$

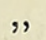

oidial

,

18

$n$
$"$
$n$
$"$,
$"$,
$"$,
$"$,
$n$

sporidial

" "

oidial$$
\text { , }
$$

sporidial

,
6 pustules on lower surface.

I pustule on lower surface.

Failed.

",

,

No" pustules, but several small black flecks of dead tissue, showing localized lethal effects of the fungus.

Ditto black
Failed-no
flecks.
Failed.

,

3 "pustules on lower surface.

I pustules on lower surface.

I pustule on lower surface and considerable number of black flecks.

I 3 pustules on lower surface.

4 pustules on lower surface.

I pustule and considerable number of black flecks.

Failed.

,)

,

Failed, but fair number of black flecks.

I pustule on lower surface.

2 pustules on lower surface and few black flecks. 


\section{TABLE I (contimued)}

Daie. Plant No. Inoculation Number. Material used for Inoculation. Results.

\begin{tabular}{|c|c|c|c|c|c|c|}
\hline \multirow{15}{*}{4.6 .19} & \multirow{3}{*}{5} & 27 & \multicolumn{2}{|c|}{ sporidial germination } & \multirow{2}{*}{$\begin{array}{c}\text { good } \\
\quad, "\end{array}$} & \multirow{4}{*}{$\begin{array}{l}\text { Failed. } \\
2 \text { pustules on lower } \\
\text { surface and several } \\
\text { black flecks. } \\
\text { I pustule on lower } \\
\text { surface. } \\
\text { Failed. }\end{array}$} \\
\hline & & 28 & oidial & , & & \\
\hline & & 29 & $"$ & $"$ & ", & \\
\hline & & 30 & & $"$ & $"$ & \\
\hline & 6 & $\begin{array}{l}31 \\
32\end{array}$ & sporidial & $"$ & $"$ & Fäled, but showed a \\
\hline & & & & & & $\begin{array}{l}\text { few black flecks } \\
\text { Failed. }\end{array}$ \\
\hline & & $\begin{array}{l}33 \\
34\end{array}$ & oidial & $"$ & $"$ & $\begin{array}{l}\text { Failed. } \\
\text { Failed, but con- } \\
\text { siderable number of } \\
\text { black flecks. }\end{array}$ \\
\hline & & 35 & $"$ & $"$ & $"$ & $\begin{array}{l}2 \text { pustules on lower } \\
\text { surface, and con- } \\
\text { siderable number of } \\
\text { black flecks. }\end{array}$ \\
\hline & & 36 & $"$ & $"$ & " & $\begin{array}{l}2 \text { pustules on lower } \\
\text { surface and con- }-{ }^{2} \text { siderable number of } \\
\text { black flecks. }\end{array}$ \\
\hline & 7 & 37 & sporidial & ," & ", & $\begin{array}{l}\text { I pustule on lower } \\
\text { surface. Many black } \\
\text { flecks. }\end{array}$ \\
\hline & & $3^{8}$ & ", & $"$ & $"$ & $\begin{array}{l}\text { Failed, but many } \\
\text { black flecks. }\end{array}$ \\
\hline & & 39 & & $"$ & " & Ditto. \\
\hline & & 40 & oldial & $"$ & $"$ & Ditto. \\
\hline & & $4 \mathrm{I}$ & $"$ & $"$ & $"$ & Ditto. \\
\hline & & $4^{2}$ & $"$ & $"$ & $"$ & $\begin{array}{l}\text { I pustule on lower } \\
\text { surface. Many black } \\
\text { flecks. }\end{array}$ \\
\hline
\end{tabular}

The occurrence of the black flecks of dead tissue in the inoculated areas of the leaves is interesting as showing the local lethal effects that the spores are capable of producing. They may occur with either sort of spore, and may possibly be connected with the histological changes in the cells of the leaf, which Eriksson has described in cases of negative infection, and which he regards as the visible signs of mycoplasmic entry.

8. Cytological changes in case of 'negative' infections. Eriksson describes certain changes in the protoplasm of some of the epidermal cells, which he considers are due to the penetration of the protoplasm of 'oidial' spores, lying outside, into the cavity of the epidermal cells in the form of mycoplasm.

Eriksson himself states that the channels by which the mycoplasm enters are too fine to be seen, and also admits that cases, similar to that just described, also occur side by side with normal positive infections.

In view of this and of the lack of circumstantial evidence, it would seem simpler to explain the changes he describes as local lethal effects due 


\section{Bailey.-Puccinia malvacearum and the Mycoplasm Theory. 183}

to the ungerminated spores. It may even be suggested that the spores do not germinate because they have formed within themselves some substance which is toxic to themselves, and that this same substance, on escaping, reacts even more noticeably on the cells of the plant underneath.

9. Histological distinction between growing seedlings derived from clean and 'infected' seed. The appearances described by Eriksson are similar to those which he had previously described in the case of wheat, and are open to the same criticisms which Marshall Ward ${ }^{1}$ raised at that time.

The present author has not had the opportunity of repeating this histological work, but has attempted to prove the presence or otherwise of the fungus in the, tissues by growing plants from seed onwards under conditions which afforded protection from outside infection.

The manner in which these experiments were carried out and their results are shown in the next section of this paper.

\section{Experiments in growing Hollyhock Plants from Seed UNDER CONDITIONS EXCLUDING OUTSIDE INFECTION.}

Dandeno, in the paper which has already been referred to, makes a record to the effect that he collected and planted many affected seeds, which were ' kept under conditions unfavourable to inoculation from external sources', and that in no case did rust appear on these plants. He makes no reference to the manner in which the experiment was conducted nor any reference to controls.

During the years I9I 2 to I 15 an attempt was made by the present writer to carry out a series of cultures under critical conditions. Two experiments were carried out during that time and will be described separately below.

Experiment $\mathrm{I}$.

The essential part of the apparatus used in this experiment was a large glass globe ${ }^{2}$ about 20 inches in diameter, provided with two open necks at opposite ends of one diameter.

The upper neck was about two and a half inches wide and the lower about three-quarters of an inch wide.

The upper neck was plugged up with cotton wadding through which passed a glass tube which reached almost to the bottom of the globe inside. The end of the glass tube outside the globe was bent over at a right angle and passed through a rubber cork, which in turn fitted tightly into a wide glass tube filled with cotton-wool. By attaching an aspirator to this last tube, air could be sucked out of the globe from time to time, and fresh

1 Marshall Ward : Recent Researches on the Parasitism of Fungi. Ann. Bot., 1905.

2 The globe was of the same type as that shown in Fig. 2. 
air drawn in through the filtering wad of cotton fixed in the neck of the globe.

The globe was supported over an ordinary earthenware pot, ten inches across at the top, by means of a wooden frame, which held it in such a position that, when the pot was filled with earth, the small lower neck of the globe was plunged one inch deep below the soil surface.

Eleven globes of the type just described were used in the first experiment.

Before starting the cultures, the globes were sterilized by formalin vapour in a closed chamber for $\mathbf{I} 2$ hours. On removing from the chamber, the two necks of each globe were plugged at once with sterile wads of cotton-wool, and the sterilized glass tube was inserted through the wadding in the large aperture.

The pots were then filled with good soil and the wooden frames placed on top of the pots in readiness to receive the globes.

Some clean sand was then sterilized and kept in sealed sterile tins.

When the above preparations were complete, the sterilization of the seed was carried out.

Two kinds of seed were used-some taken from single and some from double hollyhocks.

The plants from which the seed was taken were all diseased during the previous season.

The seeds were husked--i. e. removed from the carpels which enclosed them-placed in tap-water, and exhausted twice in succession by means of a Geryk pump.

They were then placed in Io per cent. (commercial) formalin for five minutes, washed in three changes of sterile tap-water, and then transferred to sterile Petri dishes.

The seed was sown as follows:

A small heap of sterilized sand was first made on top of the earth in the centre of the pot. The seed was placed on top of this by means of a pair of sterilized forceps, and a little sterile sand was poured over the seed. The cotton plug at the bottom of one of the globes was removed and the globe pressed down into the sand so that the lower neck of the globe surrounded and enclosed the seed, which might now be looked upon as lying in a cylinder of sterile sand, surrounded by the glass neck of the globe, but with free access to the open space inside the globe for the growth of its shootand a continuous layer of sand below it, through which the roots could find their way to the soil beneath. In this way the seed and the interior of the globe were protected from the entry of spores of all fungi, except those which could grow saprophytically in the soil and sand.

The seeds, and later the plants which grew from them, were watered with rain-water, which was poured on to the surface of the soil in the pots without disturbing the 'sand-lock'. Sufficient water reached the seed by 
capillarity to ensure germination. On June 7,1912 , one seed was sown under each of the globes in the manner described above.

Six of these seeds failed to germinate or produced sickly seedlings, and were replaced by fresh sterilized seed about three weeks later.

Twelve seeds from the same source, but unsterilized, were sown in small pots as controls at the same time as the first sowings were made under the globes. Two of these seeds also failed to germinate, but were not replaced.

The globes were placed in line along a bench in an unheated greenhouse, and were sheltered from direct sun by means of blinds. The control pots were placed between the globes along the bench.

The remainder of the seed was sown in an open bed just outside the greenhouse.

By the end of August two of the plants in the globes had failed-due in one case to an accident.

The remainder of the 'globe plants' had from four to six leaves apiece, and varied from about the same size as the 'pot-controls' to twice that size.

The colour of the leaves was scarcely any lighter than that of the controls in pots, but the texture of the leaves was obviously thinner. None of the plants in globes or pots showed any rust.

The plants in the outside border, examined three days later, showed slightly fuller growth, and practically every plant had a few scattered rust pustules on one or more of its leaves.

One of these slightly diseased plants was potted up on September 3, in place of one of the 'globe plants' which had failed. The shoot and leaves of this plant were pushed through the small neck of the globe, which was lowered over it. The fate of this particular plant is interesting, as it shows that the conditions inside the globes were highly favourable to the development of the fungus. When first placed under the globe it bore three infected leaves; the largest of these showed 12 immature pustules, the second largest showed one mature pustule, and the smallest showed a couple of dozen undeveloped pustules.

By October I I the three oldest leaves had died off, presumably killed by the fungus: of the remainder, two leaves, each about two inches in diameter, were covered with innumerable pustules, whilst three young leaves just emerging from the bud were, apparently, free from disease.

Three weeks later the entire plant was dead and covered with the remains of rust pustules.

This would seem to prove that the conditions inside the globes, though certainly abnormal, were not in any way such as would suppress the growth of any fungus latent in the tissues of plants growing inside the globes. Two features are also well worth noticing in the results just described: (1) that a certain development had to be reached by the young leaves before they could become visibly infected, and (2) that the density of pustules on the 
expanded leaves was even greater than that shown in any of the photographs in Eriksson's paper of leaves suffering from a 'primary' outbreak of the disease.

To return to the main experiment; from the beginning of September onwards the controls in pots began to be much troubled by greenfly and later by red spider (Tetranychus), which much interfered with their growth, and necessitated treatment with paraffin wash. Notwithstanding this, two pustules were found on one leaf of one of these controls on October II, and three weeks later another pot-control plant showed an equally light infection.

The control plants in the outside border continued to show more and more rust as the season went on, but even at the time when they finally died down, none of the plants showed that dense infection which Eriksson has ascribed to 'primary infection'.

The plants in globes were observed up till the beginning of December, when growth had ceased altogether, the greenhouse not being heated.

On December 4 each of these plants bore 8 to 9 leaves, of which the largest measured 3 inches across and was supported by a petiole 5 inches long.

No trace of rust had appeared on any of these plants, despite the proved suitability of their environment and the fact that, on Eriksson's expectation, the rust should have appeared, in bulk, by the end of September.

It was found, however, on this date that a few patches of mould were growing on the oldest leaves, which had dried up and fallen away from the crown.

These saprophytic fungi had doubtless made their way through the 'sand-lock' at the bottom of the globe.

From the middle of October to the beginning of December occasional Collembolae were seen in five of the globes. These live habitually in the soil and had doubtless worked their way up from below, and would be the means of introducing spores of saprophytic fungi.

During the whole of the experiment all the plants growing in globes had remained perfectly healthy, with the exception of one, which was recorded on September 3 as showing a small black-coloured patch on one leaf, and which subsequently developed two similar black-coloured patches on one petiole.

These affected leaves were removed through the top of the globe under sterile conditions, and were examined microscopically. No trace of rust could be found, and the black spots, which proved to be small areas of dead tissue, must be attributed to the action of Collembolae.

No further action was taken with the globes until the following spring, when, growth restarting, the aeration of the globes was recommenced.

At the end of April one leaf of one of the plants was inoculated with 
spores taken from one of the 'pot-controls' growing near' at hand. On the 2oth of the same month several pustules of Puccinia were found on the underside of the inoculated leaf, and three other leaves on the same side of the plant showed a few pustules.

The experiment was finally brought to an end on May 22, I9I3. On this date all the plants were removed from the globes and carefully examined. All had formed several new leaves during the spring, and the number of Collembolae was much increased.

None of the plants, however, with the exception of the artificially inoculated one just referred to, showed any sign of rust.

The 'pot-controls' were also examined on this date. These had kept their leaves during the winter and the rust had made steady progress. Three of these control plants are recorded as being 'heavily infected ', two as being 'moderately infected', and the remaining four as 'slightly' or 'very slightly infected'.

The plants in the border outside had been grubbed up during the winter, and, consequently, no record is available.

\section{Summary of Results of Experiment I.}

The cultures were started during June I9I 2 , and were continued until the middle of May i913. No rust appeared on any of the protected plants throughout the experiment, though, on Eriksson's expectation, a 'primary' outbreak might have been expected by the end of September at latest. The controls in the same house first showed rust on October II, but only a few pustules. The rust progressed slowly throughout the winter, and by April I9I3 the majority of these plants showed a fairly heavy infection. The controls in the bed outside first showed slight infection on September 3, and this increased as the season went on, but never reached 'primary' intensity.

One of the 'globe plants' was inoculated, towards the end of April, and gave a positive result.

At the beginning of September a slightly diseased plant, growing amongst the outdoor controls, was potted up underneath a globe. A month later some of the leaves of this plant showed extremely heavy infection, recalling Eriksson's description of 'primary infection'. After seven weeks the plant had been killed outright. The condition inside the globes would therefore appear to be favourable to the fungus.

\section{Experiment 2.}

In this series of cultures an attempt was made to improve on the conditions in the former experiments as follows : (I) by installing a system of continuous regulated aeration of the globes. (This would also have the effect of reducing the humidity of the atmosphere inside the globes.) 
(2) by taking steps to exclude the entry of Collembolae, \&c.

With these objects in view the globes were fitted with large cork bungs replacing the cotton wads in the upper apertures. Each cork was bored to receive three tubes. In the centre a short wide tube, ordinarily plugged with cotton-wool, but available for the passage of any instruments, \&c., necessary for inoculating or for withdrawing single leaves for examination; on one side of the central tube a small inlet-tube, penetrating only a little way into the globe and with its exterior end passing into a wide tube, plugged with cotton, to act as a filter. The third tube was the one used for withdrawing the air: this one was bent to follow roughly the inside curve of the globe, and had its internal opening close to the bottom of the globe ; the external portion of this tube passed into a cotton-plugged tube, designed to act as a germ-filter in case the aspirator should fail.

To the other end of this germ-filter was attached a tube which ran down into a small gas-jar and dipped below the surface of some water contained in the jar. A cork was inserted in the top of the gas-jar, and through this another short tube was connected by pressure tubing to a long gas-pipe, which passed in front of all the globes, and was, in turn, connected to an aspirator, which thus served to draw a continuous current of air through all the globes. The rate of the air current was equalized in each globe by watching the rate at which the air bubbled through the water in the gas-jars, and adjusting a pressure-clip, placed on one of the rubber connexions, so as to make the 'bubble rate' the same in each case.

Owing to the shape of the upper neck of the globes, it was found difficult to get a 'spore-tight' fit with the bung alone, and, to ensure this, it was found to be necessary to stretch a piece of rubber tissue tightly over the cork in each case before pushing it in.

The general appearance of these globes, when in action, is shown in Fig. 2.

In order, if possible, to exclude Collembolae, the earth used in this experiment was sterilized before starting, and, in addition, a layer of sterilized sand, one inch deep, was spread over the entire surface of the soil immediately before planting the seed.

Finally a piece of fine muslin was tied over the bottom of the pot to protect the drainage hole.

The soil sterilization was carried out as follows:

The soil was thrown into a large metal bin and sprinkled during the process with toluene; cloths were then put on top and weighted down, and the bin was covered and left for 20 hours. At the end of that time the soil was tipped out on a clean cement floor, and stirred over four times in the two succeeding days.

It was then put straight into the pots, which, together with the crocks, had been sterilized previously in a strong solution of formalin. 
Bailey.-Puccinia malvacearum and the Mycoplasm Theory'. I89

In spite of these precautions, Collembolae did again appear, though very sparingly. This must be attributed to the fact that the plants were watered with tap-water owing to the impossibility of sterilizing sufficient water to meet the daily needs of the plants in summer.

The globes and tubes were sterilized with formalin vapour as before, and the corks and all rubber parts were immersed in rectified spirit for

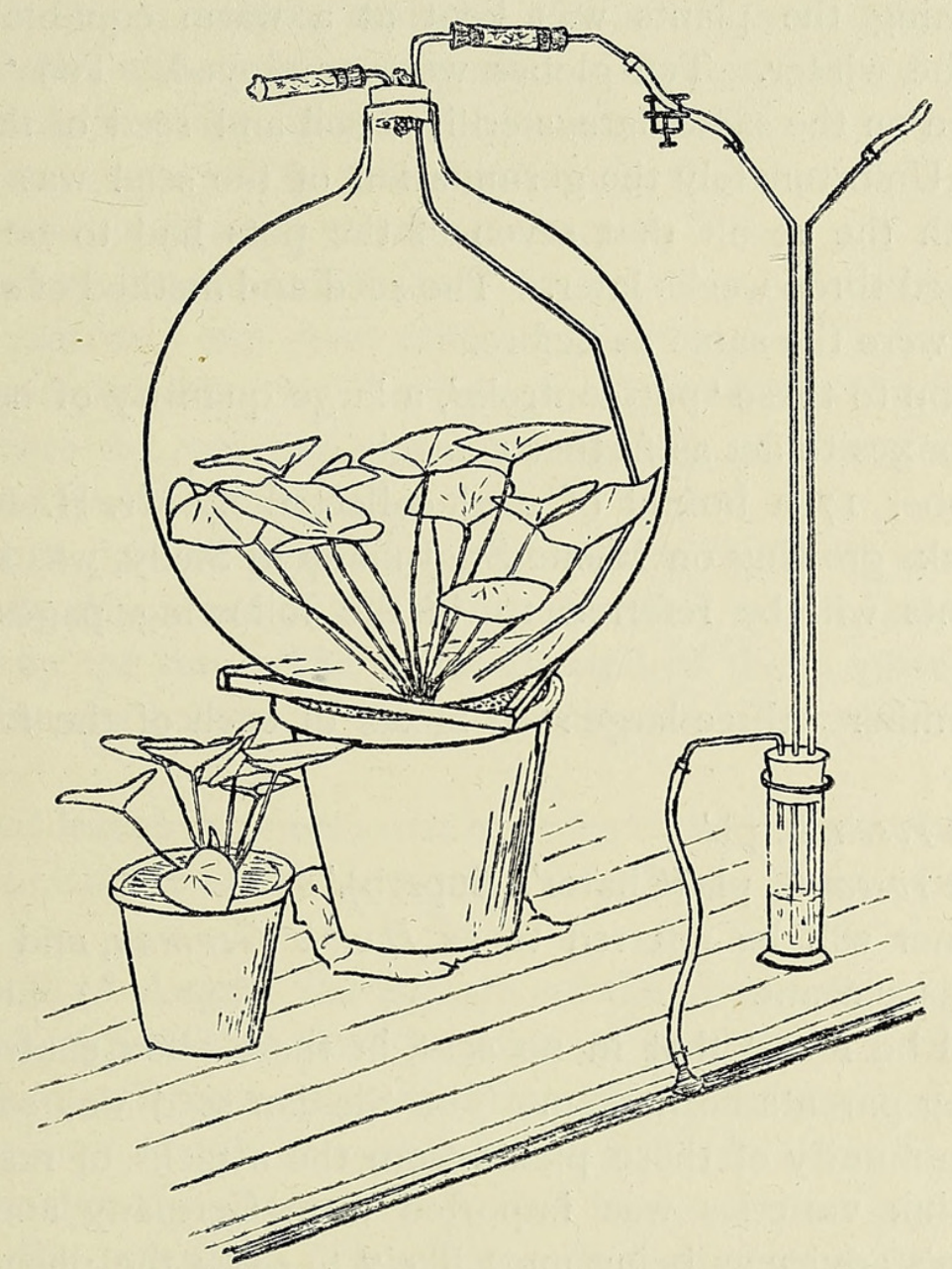

FIG. 2. Hollyhock Globe No. 9 and Control Pot No. $;$ (from a photograph taken on June 27, 1914)。

the same purpose. In addition to the formalin treatment, all the glassware was rinsed over with rectified spirit shortly before starting the experiment.

The seed used in the globes and pot"controls for this experiment was collected in October I9I 3 from some double hollyhocks with reddish magenta flowers, which had shown a considerable amount of rust on leaves, stems, and calyx, and also on the carpels themselves during the foregoing season.

In order to avoid trouble from seeds failing to germinate, they were 
not placed under the globes until the radicle had begun to push through the seed-coat. Otherwise the method of sowing the seed was the same as in the first case.

Sterilization was effected in I per cent. mercuric chloride for 8 minutes, and the seeds were subsequently washed in six changes of sterile tap-water before being left to germinate under sterile conditions.

The seed was sown under the globes on November 3, I9I3, and the house containing the plants was kept at a warm equable temperature throughout the winter. Ten globes were employed. Ten 'pot-controls' were also sown on the same date, sterilized soil and seed of the same kind being used. Unfortunately the germination of the seed was not tested in this case, with the result that seven of the pots had to be resown with germinated seed three weeks later. The seed and method of sterilization in this last case were the same as before.

In addition to these 'pot-controls', a large quantity of hollyhock seed was sown in boxes to act as further controls.

On October I7 a boxful of seed, collected by Mr. H. Festing Jones from hollyhocks growing on Monte St. Juliano in Sicily, was sown, and the resulting plants will be referred to in the following pages as Sicilian hollyhocks.

On November 3 three large seed boxes of each of the following were sown :

'Althaea rosea, fl. pl.'

'Althaea rosea, fl. pl. (Chater's Superb).'

The former will be referred to as Double German, and the latter as Chater's in this account.

It should be noted that in no case, in these 'box-controls', had the seed-producing parents been seen. The Sicilian seed was sown owing to the reputed immunity of these plants from the attacks of rust. The seed of the two pink varieties was imported from Germany and selected on Prof. Eriksson's advice as being most likely to show the phenomena which he had described in his paper.

The seed in boxes in all cases germinated well.

Early in February I9I4 and again in March the house was fumigated with nicotine without injurious effect to the foliage of any of the plants. On February 7 the benches, \&c., were scrubbed down with formalin and water ; this latter operation caused the controls to exhibit slight 'fumigation injury'.

Throughout the year the cotton plugs and rubber connexions frequently required changing.

All plants grew on steadily during the winter and subsequent summer, and by the end of April 19I4 the plants growing in boxes were cramped for lack of room. Twelve Sicilian plants were therefore potted up, as were 
also I 8 plants of each of the two double pink varieties. These pots were kept in the same greenhouse as the globes.

Two dozen plants of each of these three kinds were planted out at the same time in a garden half a mile distant.

On May I, I9I4, each of the plants in the globes had from 7 to 10 leaves, the largest of which measured $4 \frac{1}{2}$ inches across and was borne on a stalk to inches long. The 'pot-controls' were somewhat smaller and bore only about six leaves apiece, and the plants which had been started in boxes were smaller still, owing to a period of overcrowding.

At this date the plants in the globes were lighter in colour and their leaves were less rugose than those grown in the normal way, but they appeared to be more vigorous than the controls.

At the end of June the difference in size between the 'globe' plants and the 'pot-controls' was even more striking, as will be seen in Fig. 2, which is drawn to scale from a photograph taken on that date.

At this date no rust had appeared on any of the plants, including those which had been planted out.

. In the early part of July, during a sudden burst of sunshine on an otherwise cloudy day, most of the fully expanded leaves inside the globes were scorched by the sun. The worst affected of these subsequently died, and, dropping to the bottom of the globes, became infested with saprophytic moulds.

These dead leaves were removed in order to keep down the saprophytic fungi, and in the course of this operation the globes had to be opened for a short time.

At the end of August the growth of the plants in globes was still good compared with that of the four sorts of controls in pots in the same house, which had suffered a good deal from the attacks of red spider.

All the plants inside the greenhouse still remained free from rust, despite the fact that the plants which had been set out in the open now showed a plentiful infection. These latter had all sent up flowering spikes, and the rust was distributed over all except the very youngest leaves, which were unaffected except in very rare instances.

The pustules on the older leaves at the bottom of these plants were in a more advanced stage than those farther up, and were obviously the result of an earlier infection.

The plants which had been started in boxes and subsequently potted up had made very poor progress, and on August 22 they were repotted and stood outside under a north wall.

On September 5, ten months after the start of the experiment, the plants in the greenhouse still showed no sign of disease, though this was three months after the latest possible expectation on the Mycoplasm Hypothesis. 
To test whether the conditions were entirely inimical to the growth of the fungus, a bunch of heavily infected hollyhock leaves was shaken in all parts of the greenhouse. Seventeen days later, as the result of this, six of the pot-controls showed one pustule each. In five cases out of six this pustule appeared on a fully-developed leaf; in the remaining one case it occurred on a young leaf. The plants in the globes remained unaffected.

The plants in pots, standing in the open, were also examined on this date (Sept. 22) and were found to show the beginnings of infection; 60 per cent. showed a few pustules, almost entirely on the middle-aged, fully expanded leaves.

The experiment having now run so long ( $\mathrm{1} \circ \frac{1}{2}$ months), it was found that the rubber-tissue between the cork and the neck of the globes had perished, and the apparatus could no longer be relied on effectively to exclude air-borne spores.

It was decided, however, not to replace the perished rubber, but to keep the apparatus running whilst certain inoculation experiments were tried.

No observations were made on the plants in the globes during the next month, with the exception of one which was inoculated on September 29 and again on October 6 by spraying it with a suspension of germinated rust-spores.

These spores had been germinated at the bottom of a dish of sterile tap-water and were examined before they were sprayed on to the plant. In all cases, as might be expected, they had germinated in the form of 'oidia'. The results of both these inoculations were negative.

On October 28 the plants in the globes were again carefully examined, and it was found that in two cases plants were infected with rust. Neither of these two plants had been inoculated, and the inference is that they had been infected by air-borne spores owing to the faults which had developed in the apparatus as described above.

In both these cases the globes were removed, and the plants cut off at the crown and carefully examined.

The results of this examination are important, as they confirm the opinion that the infection was an external one, and not a manifestation of 'primary infection'. The fact that the pustules were of various ages shows that the disease had been running its course for some time before the plants were examined.

In the following table, 'G.G. 2' and 'G.G. 3' are the reference numbers of these cultures, and the leaves are in each case numbered from I upwards, starting with the oldest. 
TABLE II.

Ref. No. No. of leaf. $\begin{gathered}\text { Dimensions } \\ \text { (in inches). } \\ \text { Lengthof Length of } \\ \text { lamina. petiole. }\end{gathered}$

G.G. 2

$\begin{array}{lll}\text { I } & 3 \frac{1}{2} & 9 \\ 2 & ", & " \\ 4 & " & " \\ 4 & " & 7 \\ 5 & , & 7 \\ 6 & \text { " } & 7 \\ 7 & 3 & \end{array}$

8

9

I0

I I

12

13

I4

I5
I6

G.G. 3
Extent of disease.

Remarks.
No rust.

One" very small young

pustule.

One very small young

pustule.

Two young and one fairly old pustule.

One fairly old pustule.

Five young and one old pustule.

A fair number of pustules scattered irregularly over the leaf, young and old mixed indiscriminately.

Fair number, mostly young, but one old one near edge of leaf.

Fair number. Equal number of old and young pustules.

Fewer than above. All old except two.

About I50. None more than moderately old ; majority are young.

About I50. Mostly fairly old.

Five young pustules. One fairly old.

$\int_{\text {No rust. }}$ No pustules.

$$
\text { ," }
$$

Twelve young pustules scattered over surface.

No rust.

,"

An" elongated area about 2 inches long and I inch broad, situated in the extreme proximal portion of the leaf, was densely crowded with pustules varying in age from moderately old to those which were only just breaking the surface. The rest of the leaf bore about 20 pustules only, scattered irregularly except for some 5 or 6 grouped in a rough circle. These last were all old pustules.

One young pustule only.

Two pustules. One old and one young.

About 9 pustules of varying age.

O 2
These two leaves stood up in the centre of the globe.
This leaf was growing close to No. 8.

The biggest pustule from the circular colony of old pustules was examined under microscope. Found that the great majority of teleutospores had already germinated and dropped their spores. 


\section{TABLE II (continued)}

\begin{tabular}{|c|c|c|c|c|}
\hline \multirow[t]{2}{*}{ Ref. No. } & \multirow[t]{2}{*}{ No. of leaf. } & \multicolumn{2}{|c|}{$\begin{array}{l}\text { Dimensions. } \\
\text { (in inches). }\end{array}$} & \multirow[t]{2}{*}{ Extent of disease. } \\
\hline & & $\begin{array}{l}\text { Length of } \\
\text { lamina. }\end{array}$ & $\begin{array}{l}\text { Length of } \\
\text { petiole. }\end{array}$ & \\
\hline \multirow[t]{4}{*}{ G.G. 3} & 12 & $4 \frac{1}{2}$ & 6 & $\begin{array}{l}\text { About } 9 \text { pustules of varying } \\
\text { age. }\end{array}$ \\
\hline & I3 & ", & , & $\begin{array}{l}\text { About } 9 \text { pustules of varying } \\
\text { age. }\end{array}$ \\
\hline & $\begin{array}{l}I_{4} \\
\text { Expanding }\end{array}$ & $2 \frac{1}{2}$ & 4 & No rust. \\
\hline & $\begin{array}{l}\text { crown } \\
\text { leaves. }\end{array}$ & - & - & $"$ \\
\hline
\end{tabular}

Additional evidence of these being cases of outside infection is afforded in the further behaviour of 'G.G. 3'. The globe was replaced over the stump of this plant, from which all the leaves had been removed for examination. In due course new leaves developed from this stump, and these remained free from rust until six months later, when the globes were finally removed. ${ }^{1}$

It has been mentioned above that one of the plants in globesNo. G.G. 8 in the series-was inoculated with a suspension of oidial spores during September and October, but without result. Later on, further attempts at artificial inoculation were made on some of the other plants, but in all cases the result appeared to be negative.

A summary of the history of all the plants in globes from October 26 onwards is given in the following table. It will be observed that all the plants which had been infected finally developed rust, but only after an interval that made it appear improbable that the outbreaks were directly attributable to the inoculation.

The fact that so many plants-six out of ten-did develop disease before the end of the experiment may seem remarkable, but, as has been stated above, the apparatus was no longer reliable, and it should also be borne in mind that a continuous current of air was being sucked into the globes through whatever channel offered the least resistance, and that the control plants on the bench alongside bore rust pustules throughout this period.

With the exception of G.G. 2 and G.G. 3, all the globes had been last examined about a fortnight before the date on which they first showed rust in each case and had been described as 'free'.

1 In this connexion it is interesting to note that Massee, in 'The Diseases of Cultivated Plants', states that plants which have once recovered from the disease are immune from further attacks.

As the result of two series of experiments on this point I have satisfied myself that no such acquired immunity exists. 


\section{TABLE III.}

Ref. No.

Inoculations.

\section{Date. Method.}

G.G. I. 26.10.I4 Infected leaves shaken over open neck of globe.

\begin{tabular}{ll}
$\begin{array}{l}\text { G.G. 2. } \\
\text { G.G. 3. }\end{array}$ G.G. 4. I 9.10.I4 & \multicolumn{1}{c}{ nil } \\
Sprayed with \\
suspension of \\
teleutospores \\
which had ger- \\
minated to pro- \\
duce both spori- \\
dia and oidia.
\end{tabular}

First appearance of rust.

8.12.14. Four middle-aged leaves show few pustules (average, 9 per leaf).

Details given above in Table II.

8.12.14. Eleven leaves show pustules, only the unexpanded leaves being free. Maximum number of pustules on one leaf, 64 . Average number Io per infected leaf.

\begin{abstract}
G.G. 5.
G.G. 6 .

G.G. 7.

G.G. 8 .

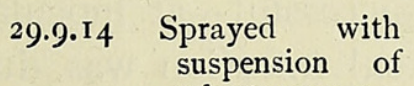
teleutospores which had germinated to form oidia.
\end{abstract}

nil.

20.II.14. Five youngish leaves affected. Maximum number of pustules on one leaf, 70 . Average number, 30 per infected leaf.
Remarks.

Rust increased rapidly, and by I2.I.15 all leaves, except the very smallest, were heavily rusted.

Rust increased rapidly, and by I2.I.I 5 the plant was mostly dead.

Last examined I3.5. I 5, when they were still free from disease.

Rust increased rapidly till by I2.I.I5 all leaves were killed with the exception of those still unexpanded.

6.I0.I 4 Ditto.

$\begin{array}{lll}\text { G.G. } 9 . & - & \text { nil. } \\ \text { G.G. I0 } & - & \text { nil. }\end{array}$

nil.

24.12.14. Three leaves (one fairly old and the other two middle-aged) show one or two incipient pustules.
Progress of disease
rapid. By I2.I.I 5
most of the leaves bore
numerous pustules, and
by $5 \cdot 3.15$ the plant
was dead.

It will be noticed that in none of these cases is the initial severity of the outbreak sufficient to place the plants in Eriksson's category of 'primary infection'. They appear, rather, to be the result of separate infections in each case, and in the case of plants which had been artificially inoculated may have arisen from teleutospores that had germinated some days after their introduction into the globes.

A final word is necessary as to the behaviour of the controls during the last stages of the experiment.

The fate of those which were planted out in April 1914 has already been described.

Those of the three kinds (Sicilian, Chater's, and Double German) which had been grown in pots under a north wall in the open first showed a few pustules on September 22. In this case also the disease continued to increase, but more slowly, until the plants died down for the winter. 
Finally, as regards the pot-controls which were kept throughout in the greenhouse: these, as shown above, failed to show any rust until artificially inoculated. They were much attacked by various pests, and their growth much stunted in consequence. The amount of rust present on them increased slowly up till December I8, I9I4, but never exceeded more than a few pustules per plant. After that date the amount of infection decreased, until in March I9I5 only one plant remained infected.

Summary of Results of Experiment 2.

The experimental plants were kept under observation for a protracted period, far beyond that claimed by Eriksson as necessary for the development of 'primary infection'.

Eriksson's period is three months from the time of sowing, when growth is continuous as in this case. In this experiment the first appearance of rust was $10 \frac{1}{2}$ months after sowing.

The observed deterioration of rubber connexions eventually admitted of outside infection.

In all, six plants out of ten in the globes developed disease. In three of these instances attempts-apparently unsuccessful-at inoculation had been made, and it is possible that the eventual infection was due to this rather than to contamination from outside. In all six the infection, to begin with, presented a 'secondary' rather than a 'primary' facies. It soon developed an intensity equal to that of 'primary infection'. One of the six plants cut down to the root and allowed to sprout again showed no recrudescence although watched for six months.

The results indicate strongly that the protected plants did not suffer from 'primary infection', though raised from seed in which, according to Eriksson's views, 'primary infection' would have been anticipated.

The control plants also in no case gave the phenomena of 'primary infection', though some, at least, were raised from seed taken from plants which were known to have been heavily infected.

Certain of the controls, when once the disease had made a start, developed the rust with a prodigality equal to that of ' primary infection'. Others remained only slightly infected to the end. The comparative immunity of these latter plants may be attributed with little hesitation to the stunting effects of red spider.

The behaviour of these particular controls contrasts strongly with that of the plants in globes. Both series of plants were slow to show infection at all, but whereas the controls, stunted by insect attacks, showed little tendency to a further development of the fungus, the plants in globes succumbed with a rapidity greater than any noted under the most favourable conditions outside. 


\section{APPENDIX.}

\section{Germination Experiments With SPORES OF PUCCINIA MALVACEARUM.}

\section{Series $I$. (July I9I4.)}

Spores scraped from young pustules on to surface of water in watchglasses.

Some of the spores sank ; others remained floating on the surface.

Only such pustules used as were brown in colour or showed only a faint trace of grey.

Pustules taken from six different hollyhock plants, all of which were growing in the garden, and had been naturally infected.

Nine cultures made :

\section{Culture.}

Sterile tap-water

2. Distilled water

3. , , , Fair.

4. Sterile tap-water. Fair.

5
6
7
8
9

Good.

Poor.

(a)

Poor.

Poor.
Spores on surface of water.

\section{Germination.}

Moderate.

Good.

Very poor.
Type.

Mostly oidial; some sporidial.

Mostly oidial ; one sporidial.

Mostly oidial ; some sporidial.

About equal propor-

tions. Onespore showed different germination

from its two cells.

Mostly oidial.

Mostly oidial ; some sporidial.

Mostly sporidial ; some oidial.

Apparently all oidial.
Spores at bottom of water.

Germination. Type.

Good. Entirely oidial.

Poor.

Moderate.

Fair.

Good. Entirely oidial.

Good. Entirely oidial.
Good.

Poor.

$$
\text { ) }
$$

Series II. (July-August I9I4.)

Entire pustules removed from leaves of naturally infected hollyhock plants, and placed on or below the surface of water in watch-glasses. Pustules taken from 3 different plants, growing in open bed.

\section{Culture.}

Spores in pustules on surface.

$$
\left.\begin{array}{c}
\text { Germinatio } \\
\text { Good. } \\
,, \\
, \\
, \\
, \\
,
\end{array}\right\}
$$

Spores in submerged pustules.

Germination. Type.

Good. All oidial.
I-4. Mixture of spori-
dial and oidial ; the
former preponderating.

5-7. Mixture of sporidial and oidial.

In two or three cases spores lying just on the surface of the water showed different types of germination from the two cells of the spore (see Fig. I). 
Culture.

8. Sterile tap-water. Good.
Spores in pustules on surface.

Germination.

Type.

Portion of pustule above water-level produced a great quantity of sporidia. Where in contact with the water at the edges it was mostly oidial.
Spores in submerged pustules.

Germination. Type.

Good.

All oidial.

\section{Series III. (May I9I9.)}

Young pustules teased out under surface of distilled water in watchglasses.

Pustules from leaf of wild plant of Malva sylvestris showing rather heavy natural infection.

Three cultures made.

Result. Germination in all three cases was poor, and two cultures never got beyond the production of very short undifferentiated germ tubes. In the remaining culture long thin tubes were produced, which in one or two cases divided up to form oidia.

Series IV. (May-June I919.)

Two diseased leaves of a naturally infected wild plant of Malva sylvestris removed and supported in such a way that one half of each leaf was immersed in water whilst the other half remained exposed.

The whole apparatus was covered with a bell-jar to ensure a moist atmosphere around the exposed portions of the leaves.

The older-looking pustules were removed before starting the experiment.

Leaf $A$.

RESULTS.

Moderately heavy infection.

\section{Submerged portion.}

Io pustules examined.

Exposed portion.

I 2 pustules examined.

Leaf $B$.

Very heavy infection, which had developed gradually.
Submerged portion.

I3 pustules examined.

Exposed portion.

I 2 pustules examined.
Germination moderate and entirely oidial.

Germination excellent in 5 cases and moderate in remaining $7.99 \%$ typical sporidial. No typical oidia.

4 had germinated very well and produced oidia only, except for a very few tubes resembling abortive pro. mycelia.

7 germinated poorly, and produced only abortive tubes suggesting promycelia which had failed to develop. I failed to germinate.

I germinated well and produced spo. ridia in quantity.

3 germinated poorly and produced sporidia only.

9 germinated well, producing sporidia only. 


\section{Series $V$. (May-June IgI9.)}

Two leaves from a plant of Malva sylvestris growing next to the one ęmployed in Series IV. Leaves treated as in Series IV.

Leaf $C$.

Moderately heavy infection.

\section{RESULTS.}

\section{Submerged portion.}

12 pustules examined.

Exposed portion.

12 pustules examined.

Leaf $D$.

Lightly infected leaf.
Submerged portion. Io pustules examined.
Exposed portion.

Io pustules examined.
6 germinated well, but for most part produced barren tubes intermediate between the two forms. A few oidia were produced, but no sporidia.

2 germinated rather poorly, producing a fair number of oidia, the rest being as above.

3 germinated poorly, producing mostly barren tubes as above, and also a few sporidia.

I germinated fairly well, producing mostly sporidia.

4 germinated well; the rest badly. Sporidia only were found in every case.

2 germinated well, forming oidia only. 1 germinated well; mostly oidia, but a few sporidia also.

I germinated moderately well, giving a few oidia and sporidia and a lot of barren abortive tubes.

4 germinated poorly, producing mostly abortive tubes, and occasionally oidia or sporidia.

2 failed to germinate.

8 germinated well and 2 poorly. Exclusively sporidial.

- Pairs or series of leaves taken from single plants. Some of these leaves were totally submerged; others were exposed to moist air.

The others entirely exposed to moist air.

Leaf.

Description.

E.

Five yellow cushions representing pustules not yet broken through. From a hollyhock plant growing in ontside border and showing slight infection.

E. I. About a dozen very young pustules.

From the same plant as leaf E.

F. About 50 pustules, chiefly collected in one corner. Of these, 7 had just broken through and were marked with Indian ink.

From naturally infected plant of Malva sylvestris growing in the open.
Treatment.

Submerged.

Exposed.

Submerged.

Leaf began to decompose before marked pustules germinated.

5 of the other pustules examined. Germination poor, but oidial only. 
Leaf.

Description.

F. I. 20 very young pustules. From same plant as $\mathrm{F}$.

About 40 young pustules evenly
distributed over leaf-surface.
From plant of Malva sylvestris,
showing fairly heavy natural
infection. Plant growing in the
open.

G. I. Similar leaf from same plant.

G. 2. Two yellow cushions not yet broken through the leaf-surface. From same plant as leaf $\mathrm{G}$.

G. 3. A bout 20 very young pustules. From same plant as $G$.

G. 4. About 20 young pustules.

Leaf from same plant as G.

G. 5. Similar leaf to last.

From same plant.

G. 6. $20-30$ pustules irregularly scat-
tered over surface. tered over surface.
From same plant.

G. 7. Similar leaf to last.

From same plant.

G. 8. Similar leaf to last.

From same plant.
Treatment.

Results.

Exposed.

Submerged.

Exposed.

Submerged.

,

Exposed.

”,

Submerged.

18 pustules examined.

Germination good in all cases.

Sporidia only produced.

Leaf decayed before pustules matured.

Leaf decayed before majority of pustules came to maturity.

5 pustules examined.

Of these one showed good germination and two fair germination.

Oidia only produced.

The remaining two germinated badly.

One of these last produced oidia only; the other a few sporidia as well.

6 pustules examined. All gave good germination, except one which germinated very badly.

Sporidia produced in every case.

5 pustules examined.

Germination good. Sporidia only produced.

9 pustules examined. All, except one, germinated well.

5 gave oidia only.

2 gave a few sporidia in addition to the oidia.

2 produced a large number of oidia, a few sporidia, and a fair number of germ tubes suggesting abortive promycelia.

5 pustules examined.

Germination good in each case. Oidia only occurred, except in one case where a few sporidia also appeared.

3 pustules examined.

Oidia only produced. 


\section{$2 \mathrm{BHL}$ Biodiversity Heritage Library}

Bailey, Irving W. 1920. "Puccinia malvacearum and the mycoplasm theory." Annals of botany 34, 173-200. https://doi.org/10.1093/aob/os-34.2.173.

View This Item Online: https://www.biodiversitylibrary.org/item/236972

DOI: https://doi.org/10.1093/aob/os-34.2.173

Permalink: https://www.biodiversitylibrary.org/partpdf/320284

\section{Holding Institution}

Smithsonian Libraries

\section{Sponsored by}

Biodiversity Heritage Library

\section{Copyright \& Reuse}

Copyright Status: Not in copyright. The BHL knows of no copyright restrictions on this item.

This document was created from content at the Biodiversity Heritage Library, the world's largest open access digital library for biodiversity literature and archives. Visit BHL at https://www.biodiversitylibrary.org. 